\title{
Diabetes Monotherapies versus Metformin-Based Combination Therapy for the Treatment of Type 2 Diabetes
}

\author{
Awadhesh K Singh (D) \\ Ritu Singh (iD) 1 \\ Partha Pratim Chakraborty ${ }^{2}$ \\ 'Department of Diabetes \& \\ Endocrinology, G.D Hospital \& Diabetes \\ Institute, Kolkata, India; ${ }^{2}$ Department of \\ Endocrinology \& Metabolism, Medical \\ College, Kolkata, India
}

\begin{abstract}
Step-wise addition of antihyperglycemic agents (AHA) after the initiation of metformin monotherapy has been the traditional approach for the treatment of type 2 diabetes mellitus (T2DM) world-wide. Emerging evidence increasingly suggests that metformin-based combination therapy, especially with the newer AHA that lowers HbA1c glucose-dependently and do not potentiate hypoglycemia, could be a potentially better option for durable glycemic control with good tolerability compared to diabetes monotherapy. In this review, we descriptively analyzed the evidence available from the systematic reviews and meta-analyses of randomized head-to-head trials that reported the efficacy and safety outcomes of diabetes monotherapy, metformin-based combination therapies, and monotherapy versus metformin-based combination therapies.
\end{abstract}

Keywords: type 2 diabetes, monotherapy, combination therapies, efficacy, safety outcomes

\section{Introduction}

The treatment of type 2 diabetes mellitus (T2DM) is primarily aimed at preventing or delaying micro- and macro-vascular complications, to curtail acute metabolic decompensation and to reduce premature death, while preserving quality of life. The pharmacological approach to treat T2DM consists of either a stepwise approach or using a combination of anti-hyperglycemic agents (AHA) from the beginning. Until recently, stepwise method of adding AHA sequentially has been the standard approach in the absence of sufficient evidence for early combination therapy supported by the American Diabetes Association and the European Association for the Study of Diabetes (ADA/EASD) consensus algorithm. ${ }^{1}$ Indeed, step-wise addition of AHA for the treatment of T2DM has been recommended in various guidelines from Asian countries including Japan, ${ }^{2}$ Korea, ${ }^{3}$ Hong Kong, ${ }^{4}$ Taiwan, ${ }^{5}$ and China. ${ }^{6}$

While monotherapy with metformin alone at the time of T2DM diagnosis allays the fear of hypoglycemia and any potential increase in side effects when compared to early combination therapy, it is also unlikely to maintain HbA1c target consistently owing to the complex patho-physiological nature of T2DM. Moreover, stepwise approach has the potential issue of both therapeutic and clinical inertia that might expose patients to a state of chronic hyperglycemia and consequently to a potential increase in risk for long-term complications of T2DM. ${ }^{7}$ Contrarily, early combination therapy could provide greater and consistent $\mathrm{HbA} 1 \mathrm{c}$ reductions owing
Correspondence: Awadhesh K Singh G.D Hospital \& Diabetes Institute, Kolkata, 700014 , India

Tel +9l 9831020428

Email draksingh_200I@yahoo.com 
to the synergistic and complementary mechanism of action (MOA). ${ }^{8}$ This could be further achieved without significantly potentiating hypoglycemia with the use of newer AHA such as sodium-glucose co-transporter-2 inhibitors (SGLT-2I), glucagon-like peptide-1 receptor agonists (GLP-1RA), and dipeptidyl peptidase-4 inhibitors (DPP4I) owing to their MOA of glucose-dependent lowering of plasma glucose. Moreover, reduction of glucotoxicity in the early stage of disease with the combination therapy may have a potential to preserve $\beta$-cell mass as well as functions besides a significant improvement in insulin sensitivity. ${ }^{9}$ Furthermore, some agents in combination therapy can counter the off-target effects of others beside complimenting the MOA of other AHA. For example, metformin, DPP-4I, and GLP-1RA can counteract the rise in glucagon levels and additionally suppress hepatic glucose production induced by SGLT-2I when used in combination. Metformin also increases GLP-1 and can further augment the GLP-1 effect in combination with DPP-4I. ${ }^{8}$ While early combination therapy with multiple AHA may be expensive and associated with reduced patient adherence because of multiple pills, this can be overcome partly by using a fixed-dose drug combination. ${ }^{10}$ Moreover, initial superior and durable glycemic control, and consequent lesser risk of complications may offset the initially higher cost of combination therapy. ${ }^{10}$ In an estimate, first-line use of dapagliflozin plus metformin combination was found to be more cost effective than metformin monotherapy and step-wise addition of dapagliflozin, in an economic analysis from Australia. ${ }^{11}$ Nonetheless, we still lack data that compared cost-effectiveness vs long-term efficacy and safety of early combination therapies.

In this review, we synthesized the findings of key efficacy and safety outcomes with monotherapies versus metformin-based combination therapy in people with T2DM. Additionally, we analyzed the efficacy and safety outcomes of different monotherapy and metformin-based combination therapies in randomized head-to-head trials.

\section{Methods}

A Boolean search from inception until April 30, 2020 was performed in PubMed electronic database using MeSH keywords with the interposition of "AND". The full text of relevant articles and cross references related to this topic in English language were retrieved. A thorough review of all head-to-head $(\mathrm{H} 2 \mathrm{H})$ randomized controlled trials (RCTs) that compared diabetes monotherapy versus metformin-based combination therapy including the systematic reviews and metaanalyses was performed. Subsequently, we synthesized the findings from all available systematic reviews and meta-analysis of RCTs that pooled and reported the efficacy (HbAlc reduction and weight loss) and key safety outcomes (hypoglycemia, gastrointestinal [GI] side effects and genito-urinary infections) of diabetes monotherapy versus metformin-based combination therapy in $\mathrm{H} 2 \mathrm{H}$ studies. The findings of systematic reviews and meta-analyses of $\mathrm{H} 2 \mathrm{H}$ studies that were conducted among diabetes monotherapy with the individual class of AHA as well as different metformin-based combination therapies, were additionally presented in this descriptive review. Network meta-analysis and efficacy and safety data of non-metformin-based combination therapies were excluded from this review.

\section{Efficacy}

Several meta-analyses of RCTs have compared the efficacy and safety outcomes of AHA either as a monotherapy or in combination therapies. In an earlier meta-analysis in 2013, Phung et al ${ }^{12}$ showed that metformin-based combination therapies (including sulfonylurea [SU], glinides, thiazolidinediones [TZD], DPP-4I and SGLT-2I, pooled together) significantly lowered $\mathrm{HbAlc}(\Delta-0.43 \%$; $95 \%$ CI, -0.56 to -0.30 ) compared to the metformin monotherapy in the study duration ranging from 16 to 76 weeks, based on 13 RCTs consisting of a total of 5370 patients with T2DM. However, there was a significant increase in risk of hypoglycemia with metformin-based combination therapies when compared to metformin alone (Risk Ratio [RR] 1.56; 95\% Confidence Interval [CI], 1.08-2.26), although no such significant difference was noted after exclusion of SU-based combination therapy (RR 1.20; 95\% CI, 0.91-1.56). Nonetheless, it was not apparent from this meta-analysis whether metformin-based combinations using a different AHA would produce similar superior reduction in HbAlc compared to the metformin monotherapy. Several subsequent meta-analyses of randomized $\mathrm{H} 2 \mathrm{H}$ trials have compared the safety and efficacy of different diabetes monotherapies, metforminbased combination therapies, and monotherapy vs metformin-based combination therapies in T2DM. ${ }^{13-20}$ The 2016 meta-analysis by Maruthur et $\mathrm{al}^{13}$ is the largest (179 trials and 25 observational studies) study having additional grading of recommendations' assessment, development and evaluation (GRADE) on the quality of strength of 
evidence. A meta-analysis by Milder et $\mathrm{al}^{17}$ also reported strength of evidence through GRADE approach.

\section{Effect on HbAlc with Diabetes Monotherapy, Metformin-Based Combination Therapy and Monotherapy versus Metformin-Based Combination}

\section{Therapies}

Table 1 summarizes the HbA1c lowering effect from different meta-analyses of randomized $\mathrm{H} 2 \mathrm{H}$ trials. Collectively, in short-term monotherapy studies, HbAlc reduction with metformin, TZDs, SUs and SGLT-2I was similar; while DPP-4I showed less effectiveness compared to metformin, SUs and SGLT-2Is. Metformin monotherapy was found to be inferior to metformin-based combination with either SUs/Glinides or TZD or DPP-4I or SGLT-2I. As expected, metformin-based combination therapy either with SUs/Glinides or TZD or DPP-4I and SGLT-2I are superior in lowering HbAlc compared to monotherapy with either agent. Notably, the combination of metformin plus TZD showed a twice as large drop in HbAlc compared to metformin monotherapy, when baseline HbA1c $\geq 8 \%$ vs $<8 \%$. While SGLT-2I plus metformin combination therapy had a small but significant difference in lowering HbA1c compared to the DPP-4I plus metformin combination, this finding was inconsistent. Largely, there was no clinically meaningful between-group difference $(\geq 0.3 \%)$ in $\mathrm{HbAlc}$ lowering with different metformin-based combinations barring combination of metformin with GLP1RA which was meaningfully superior in $\mathrm{HbA1c}$ reduction ( $\Delta-0.65 \% ; 95 \% \mathrm{CI},-0.54$ to $-0.75 \%$ ) compared to the metformin plus DPP-4I combination therapy.

\section{Effect on Body Weight with Diabetes Monotherapy, Metformin-Based Combination Therapy and Monotherapy versus Metformin-Based Combination \\ Therapies}

Table 2 summarizes the weight-lowering effects from different meta-analyses of randomized $\mathrm{H} 2 \mathrm{H}$ trials. Collectively, patients on metformin monotherapy lost more weight compared to DPP-4I, whereas patients on SGLT-2I monotherapy lost more weight compared to metformin, SU and DPP-4I monotherapy, in short-term studies extending from 12-104 weeks. A significant weight reduction was observed with metformin-based combination of each class of AHA compared to monotherapy with either SUs/Glinides or TZDs or DPP-4I or SGLT2I class. Contrarily, metformin monotherapy showed significantly more weight loss compared to metformin-SUs, metformin-TZD and metformin-DPP-4I combination therapy. Combination therapy with SGLT-2I-metformin and GLP-1RA-metformin showed a significant weight reduction compared to metformin monotherapy, while a significant weight gain was shown with SU-metformin or TZD-metformin combination compared to metformin monotherapy. Comparison between different metforminbased combinations has yielded similar trends. Weight reduction was significantly larger with SGLT-2I plus metformin combination vs metformin plus non-SGLT-2I combination including metformin-DPP-4I combination.

\section{Safety}

Hypoglycemia with Diabetes

Monotherapy, Metformin-Based Combination Therapy and Monotherapy versus Metformin-Based Combination

\section{Therapies}

Table 3 summarizes the hypoglycemia outcome from different meta-analyses of randomized $\mathrm{H} 2 \mathrm{H}$ trials. Collectively, no difference in hypoglycemic rate was observed between metformin vs DPP4I- vs SGLT2Imonotherapy, while treatment with SUs was associated with a significantly increased risk of all forms of hypoglycemia (mild, moderate, and severe) when used either as monotherapy or in combination with metformin (compared to TZD, DPP-4I, SGLT-2I and GLP-1RA). No apparent increase in hypoglycemic risk was observed with metformin-based combination therapy of DPP-4I and SGLT-2I compared to monotherapy with either agent. Among different metformin-based combination therapies, no major difference in hypoglycemia was observed between SGLT2I-metformin vs DPP-4I-metformin combination.

\section{GI Side Effect with Diabetes} Monotherapy, Metformin-Based Combination Therapy and Monotherapy versus Metformin-Based Combination

\section{Therapies}

Table 4 summarizes the GI side effects of AHA from different meta-analyses of randomized $\mathrm{H} 2 \mathrm{H}$ trials. Collectively, any GI side effects including nausea, 


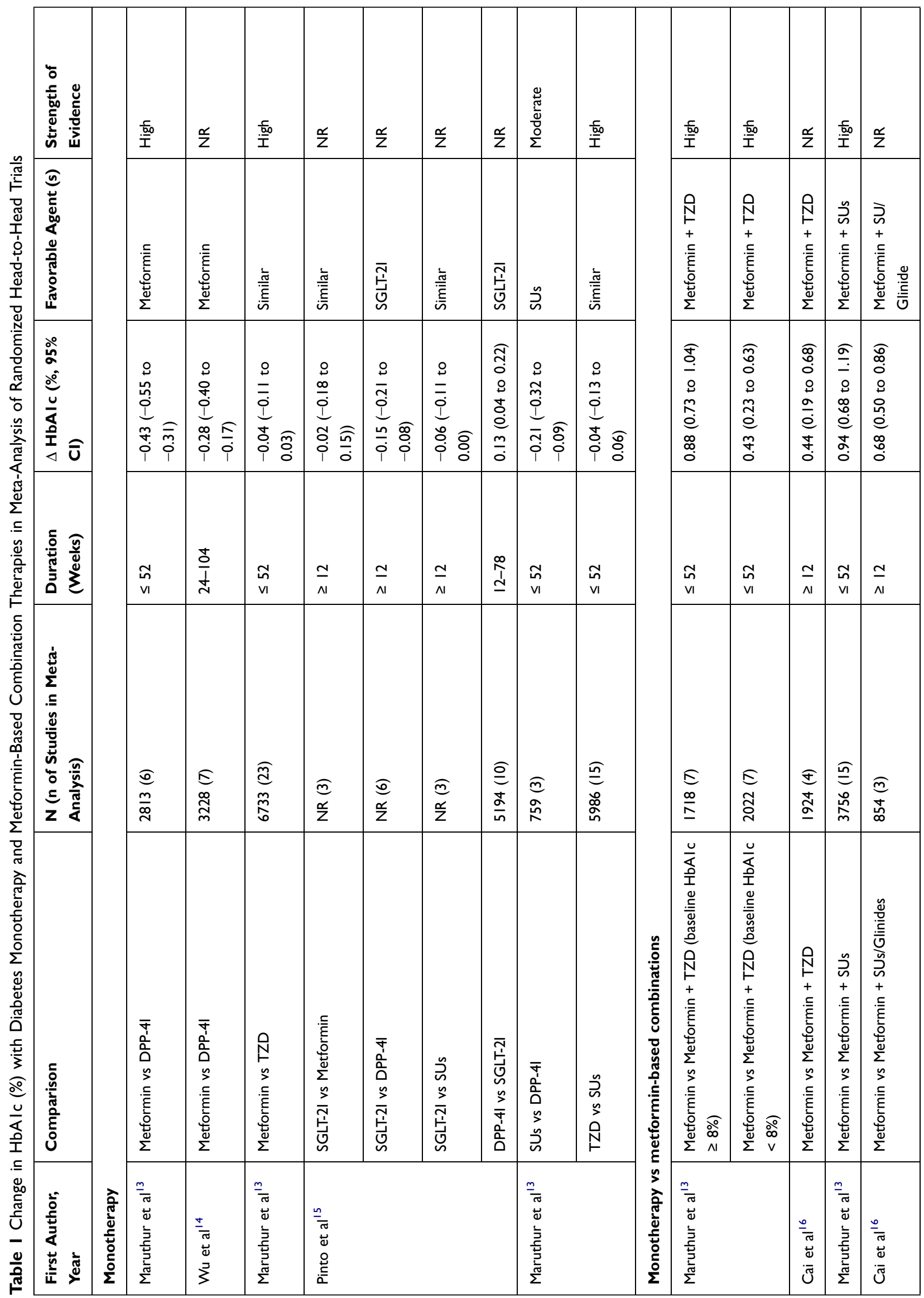




\begin{tabular}{|c|c|c|c|c|c|c|c|c|c|c|c|c|}
\hline 点呫 & $\frac{\alpha}{z}$ & $\frac{\alpha}{z}$ & $\begin{array}{l}\text { 嘉 } \\
\text { In }\end{array}$ & 号 & 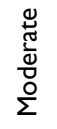 & 亳 & 足 & 品 & 号 & 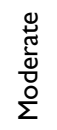 & 号 & 号 \\
\hline 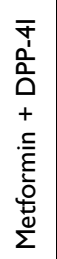 & 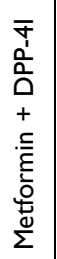 & 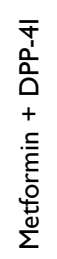 & 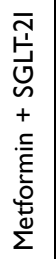 & 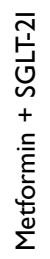 & 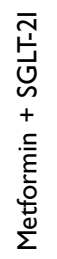 & 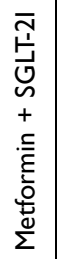 & 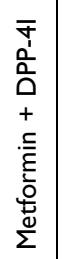 & 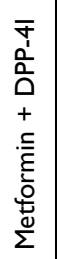 & 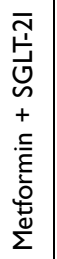 & 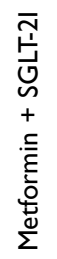 & 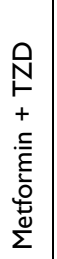 & 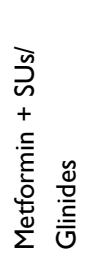 \\
\hline $\begin{array}{l}\widehat{\rho} \\
0 \\
0 \\
\dot{0} \\
0 \\
0 \\
0 \\
0 \\
0 \\
0\end{array}$ & 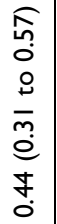 & 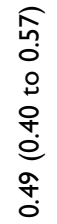 & 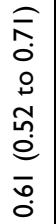 & 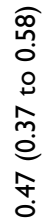 & 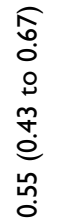 & 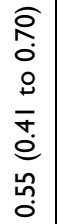 & 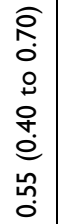 & $\begin{array}{l}\sigma \\
\sigma \\
0 \\
0 \\
0 \\
\infty \\
0 \\
0 \\
0 \\
\infty \\
\infty \\
0\end{array}$ & 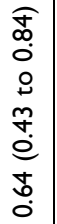 & 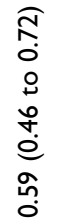 & $\begin{array}{l}\widehat{\sigma} \\
\text { o } \\
0 \\
0 \\
\infty \\
0 \\
0 \\
0 \\
0 \\
\infty \\
0 \\
0\end{array}$ & 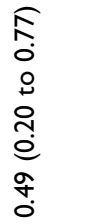 \\
\hline
\end{tabular}

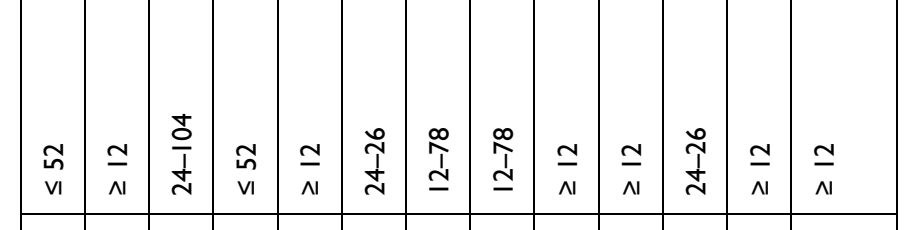
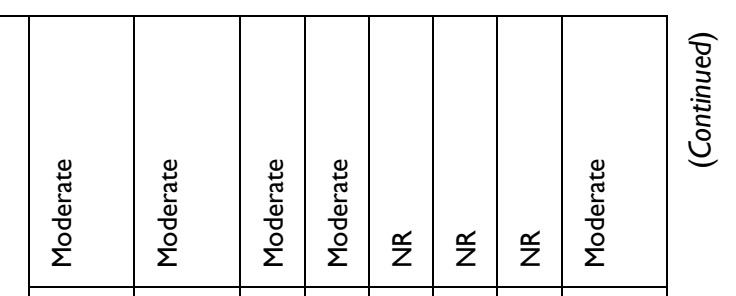

\begin{tabular}{|c|c|c|c|c|c|c|c|}
\hline 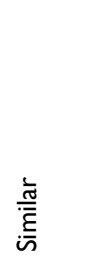 & 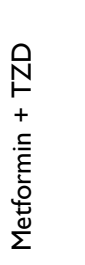 & 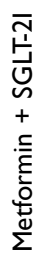 & 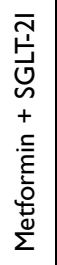 & $\begin{array}{l}\frac{\bar{E}}{\overline{\bar{E}}} \\
i \bar{n}\end{array}$ & $\begin{array}{l}\frac{\bar{c}}{\overline{\underline{\epsilon}}} \\
\text { in }\end{array}$ & 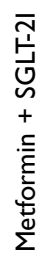 & 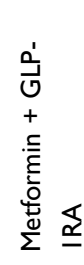 \\
\hline 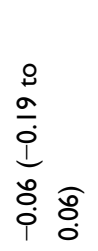 & 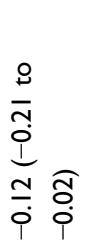 & $\begin{array}{l}\text { Oे } \\
0 \\
0 \\
\stackrel{0}{0} \\
0 \\
0 \\
\\
0\end{array}$ & 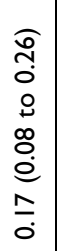 & 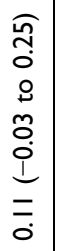 & $\begin{array}{l}0 \\
0 \\
0 \\
0 \\
0 \\
0 \\
0 \\
1 \\
1 \\
0 \\
0 \\
0\end{array}$ & $\begin{array}{l}\widehat{ָ} \\
0 \\
0 \\
\dot{0} \\
m \\
0 \\
0 \\
\overline{0} \\
0\end{array}$ & \begin{tabular}{l}
$\hat{n}$ \\
$\hat{0}$ \\
0 \\
0 \\
\multirow{0}{0}{} \\
0 \\
0 \\
0 \\
0 \\
0
\end{tabular} \\
\hline
\end{tabular}

\begin{tabular}{|c|c|c|c|c|c|c|c|}
\hline $\begin{array}{l}\hat{N} \\
\text { vi }\end{array}$ & $\begin{array}{l}\text { N } \\
\text { v }\end{array}$ & 므 & $\begin{array}{l}\text { ก̃ } \\
\mathrm{v}\end{array}$ & $\stackrel{\infty}{\stackrel{\infty}{\simeq}}$ & $\begin{array}{l}\text { N } \\
\text { v1 }\end{array}$ & $\begin{array}{l}\text { గn } \\
\text { N1 }\end{array}$ & $\begin{array}{l}\hat{n} \\
\text { vi }\end{array}$ \\
\hline
\end{tabular}

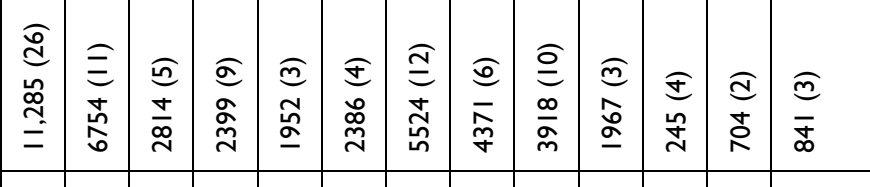

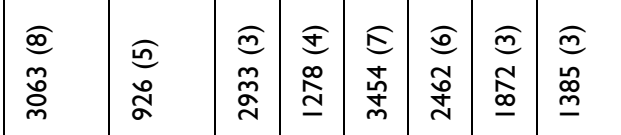

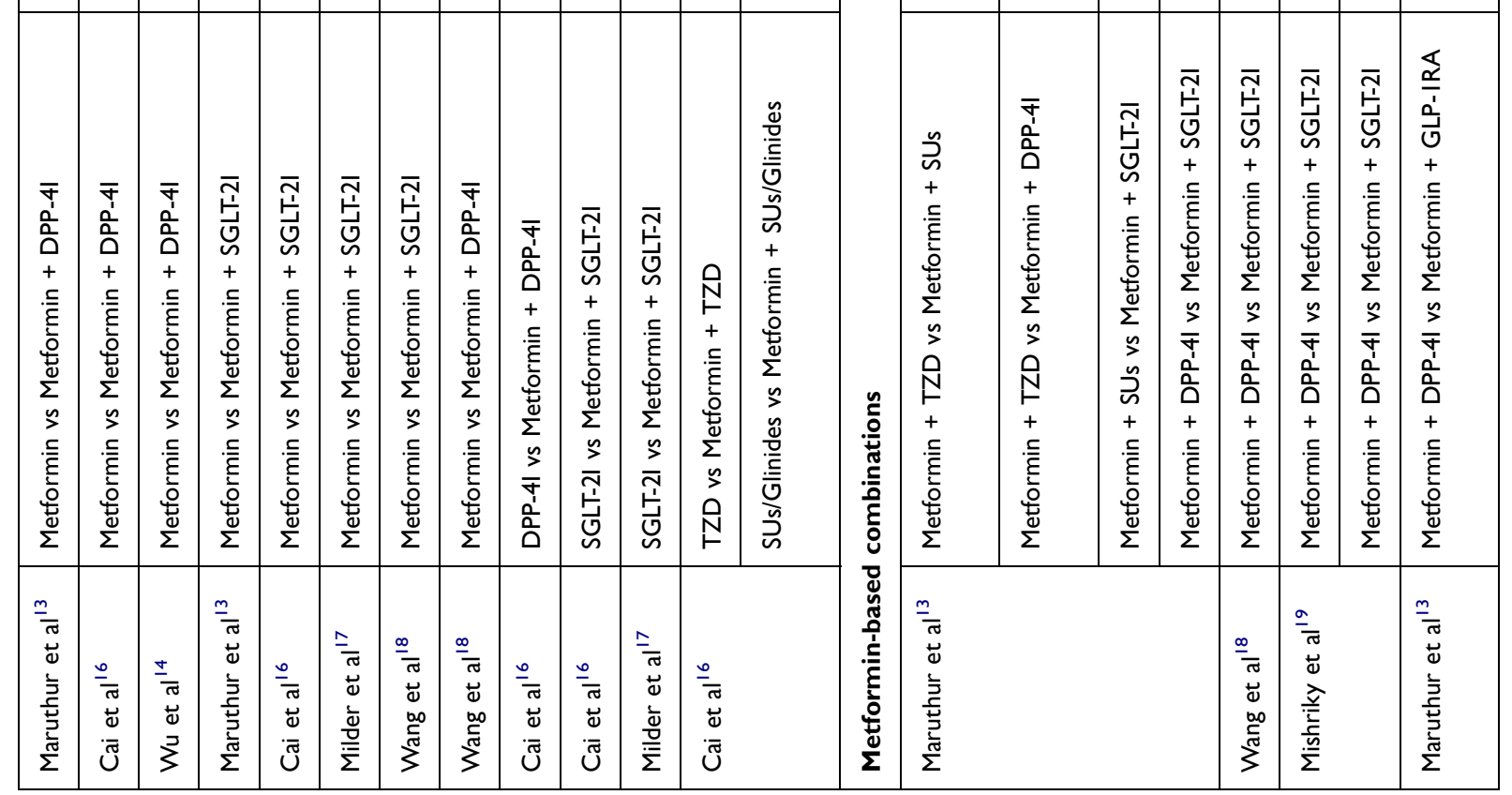




\begin{tabular}{|c|c|c|c|}
\hline 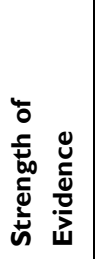 & $\frac{o}{Z}$ & 方 & $\frac{\alpha}{Z}$ \\
\hline 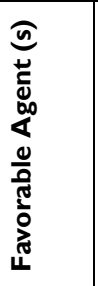 & 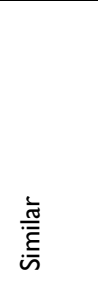 & 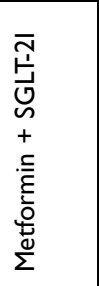 & 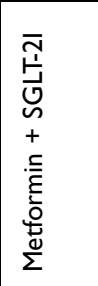 \\
\hline 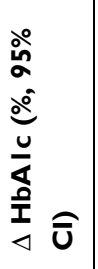 & 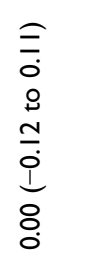 & 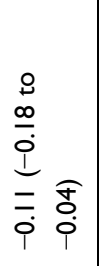 & 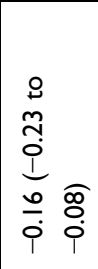 \\
\hline 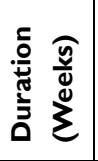 & $\stackrel{\sim}{\sim}$ & กิ & 吉 \\
\hline 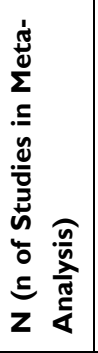 & $\begin{array}{l}\widehat{o} \\
\stackrel{a}{o} \\
\stackrel{o}{\sigma}\end{array}$ & $\begin{array}{l}\widehat{0} \\
\hat{0} \\
\text { bे }\end{array}$ & $\begin{array}{l}\text { an } \\
\text { مे }\end{array}$ \\
\hline 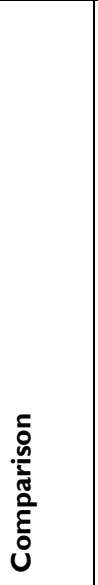 & 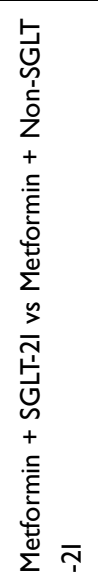 & 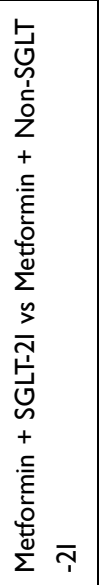 & 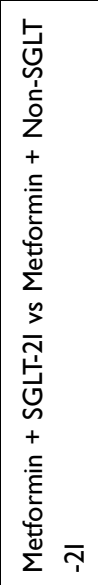 \\
\hline 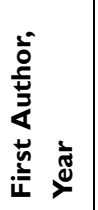 & $\begin{array}{l}\frac{8}{0} \\
\frac{0}{\pi} \\
\stackrel{0}{J} \\
\end{array}$ & & \\
\hline
\end{tabular}

vomiting or diarrhea were more frequently observed with metformin and GLP-1RA either in monotherapy or with combinations, compared to SUs, TZDs or DPP-4I and SGLT-2I monotherapy. In monotherapy studies, GI events are fewer with metformin compared to GLP-1RA. No significant difference in GI events was noted with metformin-based combination when compared to metformin monotherapy. Metformin-SU combination had similar GI side effects compared to metformin-DPP-4I combinations. Expectedly, metformin-GLP-1RA combination had higher GI side effects compared to metformin-DPP-4I combinations.

\section{Genito-Urinary Infections with SGLT-2 versus Non-SGLT-2-Based Therapies}

RCTs that studied SGLT-2I either as monotherapy or combination therapy with metformin reported the outcome of genito-urinary infections. Table 5 summarizes the genito-urinary side effects of AHA from different metaanalyses of randomized $\mathrm{H} 2 \mathrm{H}$ trials. Collectively, treatment with SGLT-2I was found to be associated with a significant increase in genital tract infections (GTI) compared to metformin, SUs, DPP-4I. Interestingly, SGLT-2I plus metformin combination therapy showed significantly $31 \%$ (RR 0.69; 95\% CI, 0.50-0.96)) lower incidence of GTI compared to SGLT-2I monotherapy with moderate quality GRADE evidence. No obviously increased risk of urinary tract infections (UTI) was observed with SGLT-2I plus metformin combination therapy compared to either metformin monotherapy or metformin plus DPP-4I combination therapy.

\section{Other Safety Outcomes of Interest}

The largest meta-analysis, by Maruthur et $a 1,{ }^{13}$ did not report any increased risk of lactic acidosis with metformin, based on the limited evidence. This finding was further supported by an earlier (2010) Cochrane meta-analysis ${ }^{21}$ and later (2014) systematic reviews ${ }^{22}$ that did not report any significant increase in risk of lactic acidosis with metformin, including in people with mild to moderate chronic diabetic kidney disease. Similarly, no metaanalyses exclusively reported either any increase in risk of ketosis or fractures with SGLT-2I or any increase in heart failure with TZD or DPP-4I or any increase in pancreatitis with DPP-4I and GLP-1RA. 


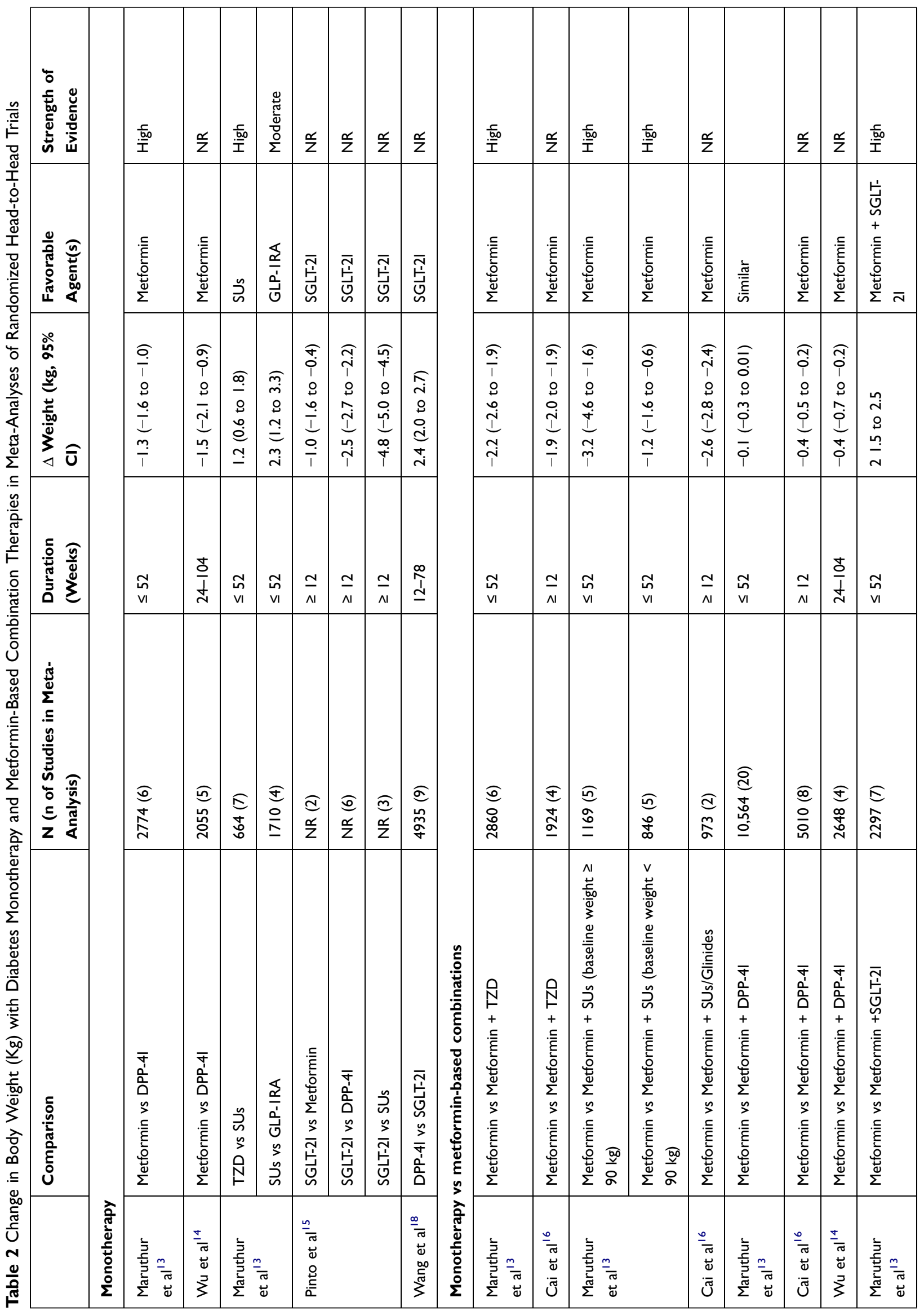




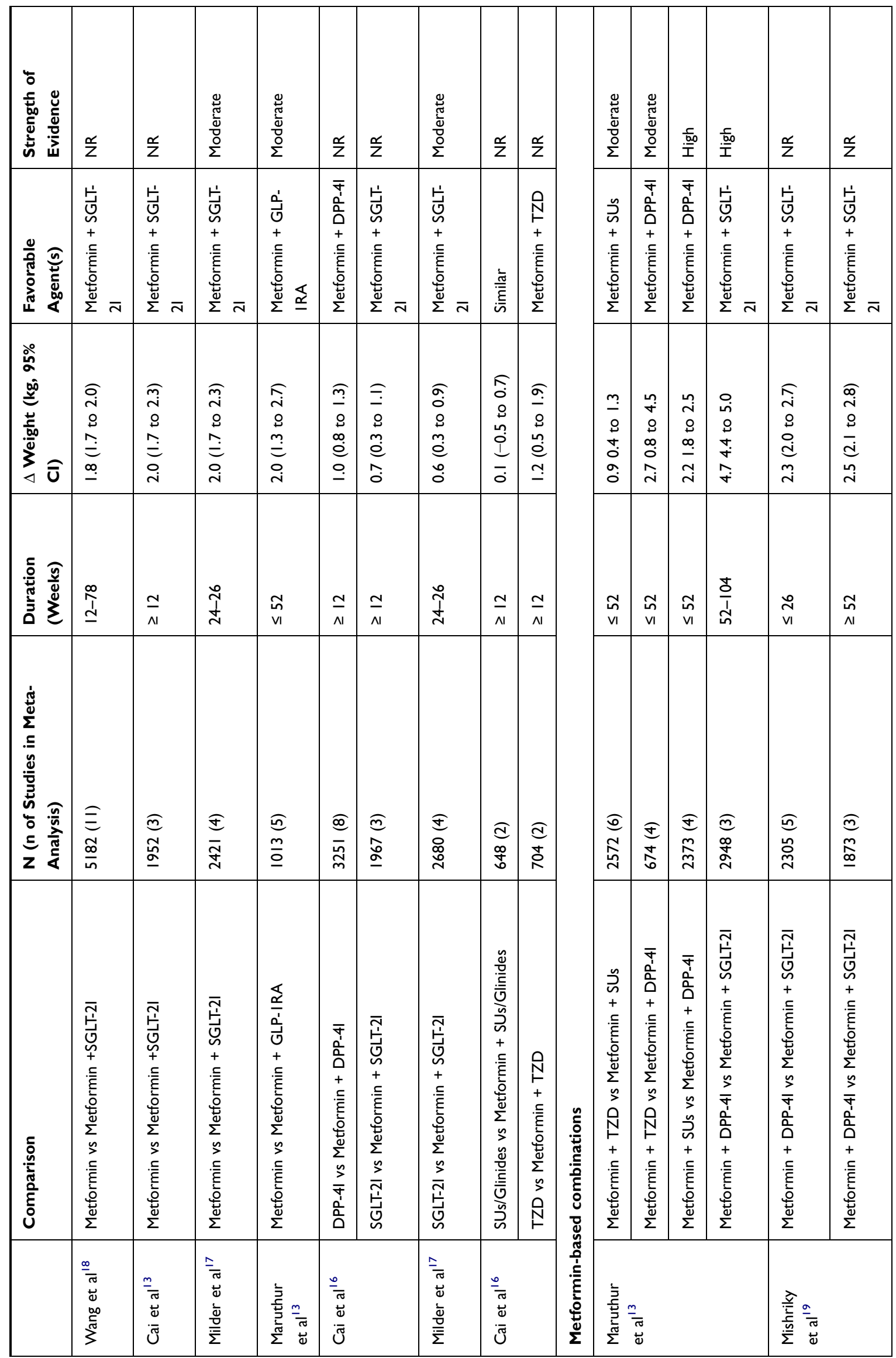




\begin{tabular}{|c|c|c|c|c|}
\hline$\stackrel{\mathscr{c}}{Z}$ & $\begin{array}{l}\stackrel{0}{0} \\
\frac{0}{0} \\
\frac{0}{0} \\
\Sigma\end{array}$ & $\stackrel{\mathscr{c}}{Z}$ & $\stackrel{\varrho}{Z}$ & $\stackrel{\mathscr{c}}{Z}$ \\
\hline 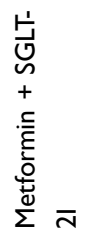 & 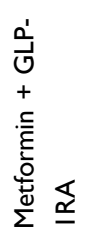 & 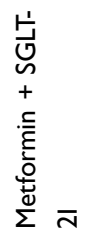 & 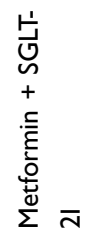 & 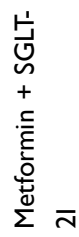 \\
\hline 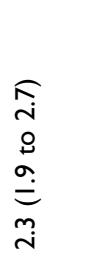 & 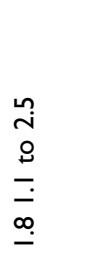 & 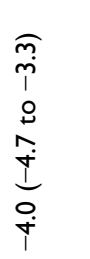 & $\begin{array}{l}\widehat{o} \\
i \\
i \\
o \\
\alpha \\
\dot{+} \\
\dot{I} \\
\dot{p} \\
\dot{p}\end{array}$ & 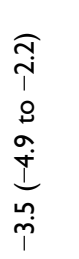 \\
\hline 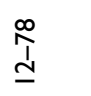 & $\begin{array}{l}\text { ก̂ } \\
\text { VI }\end{array}$ & $\stackrel{\sim}{\sim}$ & กี & 므 \\
\hline $\begin{array}{l}\widehat{o} \\
\frac{\kappa}{m}\end{array}$ & 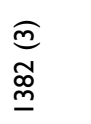 & 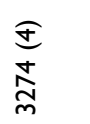 & $\begin{array}{l}\widehat{\theta} \\
\frac{\hat{y}}{\sigma}\end{array}$ & 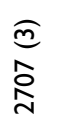 \\
\hline 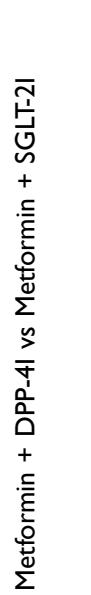 & 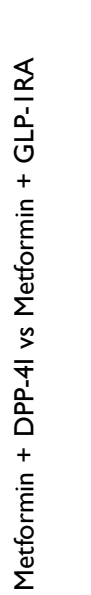 & 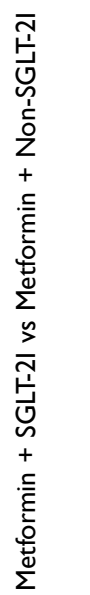 & 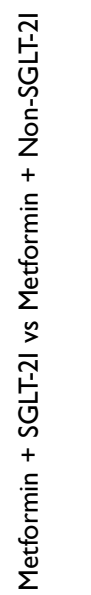 & 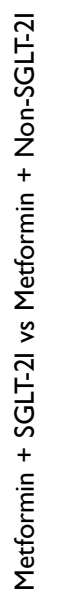 \\
\hline 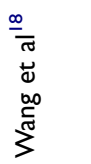 & 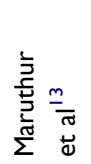 & $\begin{array}{l}\frac{\pi}{\pi} \\
\frac{\pi}{0}\end{array}$ & & \\
\hline
\end{tabular}

\section{Discussion}

Lifestyle modifications along with metformin monotherapy have been the classical approach (unless intolerant or having contraindication to metformin) to treat $\mathrm{T} 2 \mathrm{DM}$ in the absence of osmotic symptoms or severe hyperglycemia. Notably, the 2019 guidelines of the European Society of Cardiology (ESC) recommend the use of newer AHA such as SGLT-2I or GLP-1RAs in T2DM as a first-line drug in the presence of atherosclerotic cardiovascular disease (ASCVD) or high cardiovascular (CV) risks. ${ }^{23}$ While both ADA/EASD and the American Association of Clinical Endocrinologists (AACE) recommend intensification of treatment with an additional AHA once monotherapy fails to achieve or maintain an $\mathrm{HbAlc}$ target after 3 months, the $\mathrm{AACE}^{24}$ recommends combination therapy (metformin plus other AHA) with HbA1c level of 7.5\% or higher $(\geq 59 \mathrm{mmol} / \mathrm{mol})$ even at the time of T2DM diagnosis. Similarly, metformin-based combination therapy is recommended for initiation with an HbAlc level of $\geq 8.5 \%$ ( $\geq 69 \mathrm{mmol} / \mathrm{mol}$ ) in Taiwan and with HbA1c of $\geq 7.5 \%$ ( $\geq 59 \mathrm{mmol} / \mathrm{mol})$ in Korea and Hong Kong, at the time of T2DM diagnosis. Combination therapy initiation is recommended in patients with an HbAlc level of $>8.5 \%$ by the Canadian Diabetes Association. ${ }^{25}$ Combination therapy is recommended only when $\mathrm{HbA} 1 \mathrm{c}$ level is more than $1.5 \%(17 \mathrm{mmol} / \mathrm{mol})$ above the individual target in the ADA/EASD 2018 position statement, while the 2019 update recommends early combination therapy in newly diagnosed T2DM from beginning but through the shared decision-making with patients. Recently, ADA 2020 Standards of Care $^{26}$ suggested (Grade A recommendation) an early combination therapy from the beginning in some patients to avoid further escalation and extending the time to treatment failure, based on the results from the 5-year VERIFY (vildagliptin efficacy in combination with metformin for early treatment of T2DM) trial. ${ }^{27}$ Results from the VERIFY study conducted in newly diagnosed T2DM patients with mild hyperglycemia (HbA1c of 6.5-7.5\%), showed that initiation of metformin and DPP-4I combination therapy is superior to sequential intensification with regard to treatment failure over a 5-year period. The combination therapy of metforminDPP-4I had significantly lower incidence (43.6\%) of initial treatment failure (defined as $\mathrm{HbA} 1 \mathrm{c} \geq 7 \%$ on two occasions done 3 months apart) compared to monotherapy with metformin $(62.1 \%)$. Moreover, the median time to treatment failure time was also higher in the combination arm 


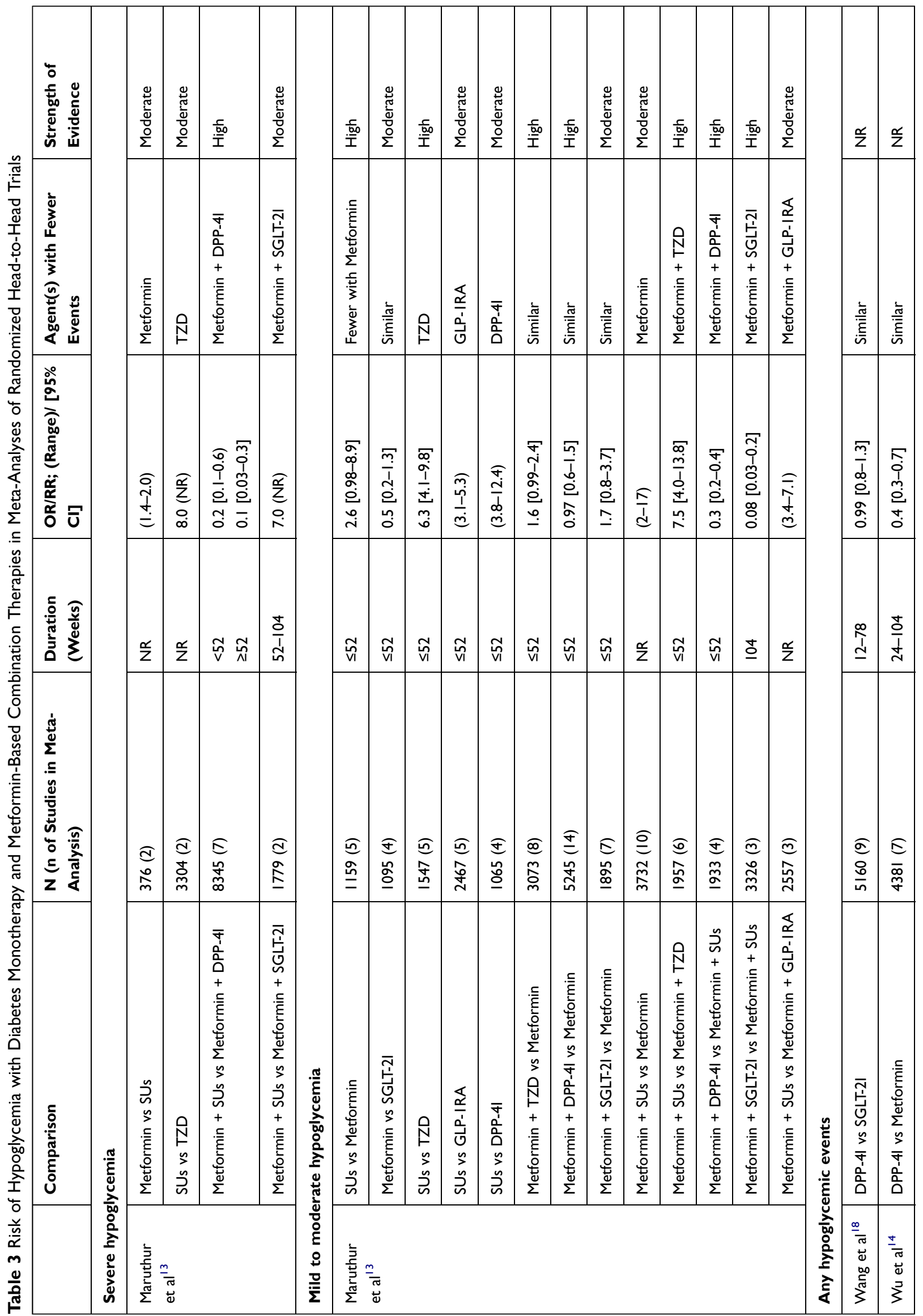




\begin{tabular}{|c|c|c|c|c|c|c|c|c|c|c|c|c|c|c|}
\hline$\stackrel{\alpha}{Z}$ & $\stackrel{\alpha}{z}$ & $\stackrel{\alpha}{Z}$ & $\frac{\mathscr{c}}{z}$ & $\stackrel{\alpha}{Z}$ & $\frac{\alpha}{z}$ & 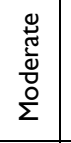 & 寽 & 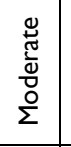 & 号 & 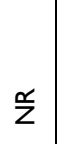 & $\frac{\alpha}{z}$ & $\stackrel{\alpha}{Z}$ & $\stackrel{\alpha}{Z}$ & $\frac{\alpha}{Z}$ \\
\hline 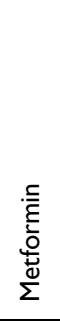 & $\begin{array}{l}\frac{\bar{c}}{\overline{\underline{E}}} \\
\frac{\bar{\varepsilon}}{\bar{n}}\end{array}$ & $\begin{array}{l}\frac{\bar{E}}{\overline{\underline{E}}} \\
\frac{\bar{E}}{\bar{s}}\end{array}$ & 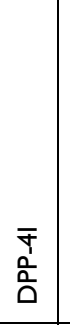 & $\begin{array}{l}\frac{\overline{\bar{c}}}{\overline{\bar{E}}} \\
\frac{\bar{\varepsilon}}{\bar{n}}\end{array}$ & $\begin{array}{l}\frac{\overline{\bar{t}}}{\overline{\overline{\underline{E}}}} \\
\bar{n}\end{array}$ & $\begin{array}{l}\frac{\bar{d}}{\overline{\frac{\omega}{E}}} \\
\frac{i}{\bar{E}}\end{array}$ & 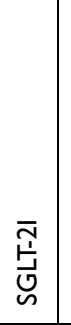 & $\begin{array}{l}\frac{\bar{c}}{\overline{\bar{E}}} \\
\frac{\bar{E}}{\bar{n}}\end{array}$ & 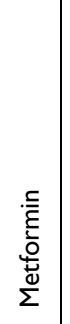 & 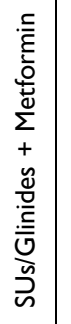 & 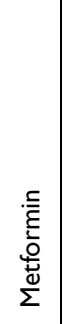 & $\begin{array}{l}\frac{\bar{c}}{\overline{\bar{E}}} \\
\frac{\bar{E}}{\bar{n}}\end{array}$ & $\frac{\text { 亯 }}{\overline{\underline{E}}}$ & 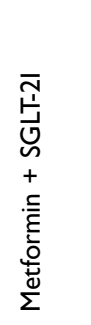 \\
\hline 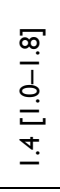 & 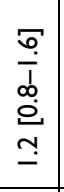 & $\begin{array}{l}\frac{\Gamma}{T} \\
\hat{1} \\
\hat{0} \\
0 \\
\underline{0}\end{array}$ & 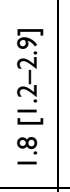 & $\begin{array}{l}\square \\
\bar{\sigma} \\
\infty \\
0 \\
0 \\
= \\
=\end{array}$ & 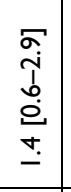 & 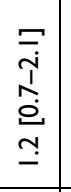 & 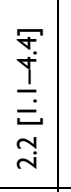 & 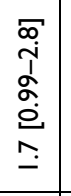 & 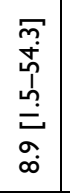 & $\begin{array}{l}\infty \\
0 \\
0 \\
\omega \\
0 \\
0 \\
0 \\
0\end{array}$ & $\begin{array}{l}\underset{n}{\tilde{i}} \\
\underline{I} \\
\dot{\Xi} \\
\stackrel{0}{-}\end{array}$ & 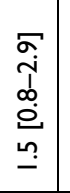 & $\begin{array}{l}\frac{m}{\bar{m}} \\
\bar{\phi} \\
\stackrel{0}{0} \\
\stackrel{-}{-}\end{array}$ & $\begin{array}{l}\infty \\
0 \\
\frac{1}{0} \\
0 \\
m \\
0 \\
0\end{array}$ \\
\hline$\stackrel{\infty}{\stackrel{\infty}{\perp}}$ & $\frac{\sim}{\wedge 1}$ & 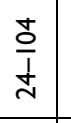 & $\stackrel{\simeq}{\wedge}$ & $\stackrel{\infty}{\stackrel{\infty}{\perp}}$ & $\frac{N}{\wedge 1}$ & $\underset{\sim}{\stackrel{\sim}{\sim}}$ & $\stackrel{\simeq}{\wedge}$ & $\underset{\text { I }}{\stackrel{\text { I }}{\mathbf{n}}}$ & $\begin{array}{l}\simeq \\
\wedge 1\end{array}$ & $\begin{array}{l}\simeq \\
\wedge 1\end{array}$ & $\frac{\sim}{\wedge 1}$ & $\begin{array}{l}\simeq \\
\wedge 1\end{array}$ & $\stackrel{\infty}{\stackrel{\infty}{\perp}}$ & $\begin{array}{l}\frac{t}{0} \\
\frac{1}{0} \\
\text { N }\end{array}$ \\
\hline $\begin{array}{l}\widehat{n} \\
\frac{0}{2} \\
\frac{0}{n}\end{array}$ & 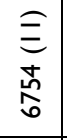 & 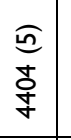 & 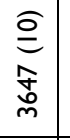 & \begin{tabular}{l}
$\widehat{\infty}$ \\
\multirow{N}{\hat{\sigma}}{} \\
$\hat{f}$
\end{tabular} & $\begin{array}{l}\widehat{\tilde{n}} \\
\stackrel{\infty}{\infty} \\
\stackrel{\sim}{=}\end{array}$ & 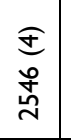 & $\begin{array}{l}\widehat{\tilde{m}} \\
\stackrel{\circ}{ \pm} \\
\stackrel{ \pm}{=}\end{array}$ & 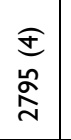 & 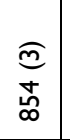 & $\begin{array}{l}\widehat{0} \\
\bar{\infty} \\
\bar{\infty}\end{array}$ & 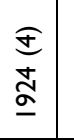 & $\begin{array}{l}\text { d } \\
\stackrel{0}{R}\end{array}$ & 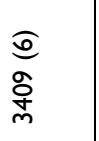 & $\begin{array}{l}\hat{e} \\
\tilde{m} \\
\hat{q}\end{array}$ \\
\hline 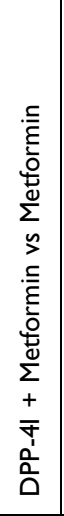 & 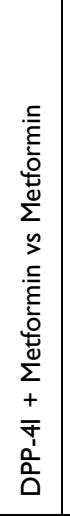 & 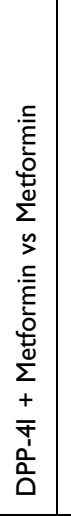 & 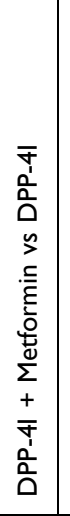 & 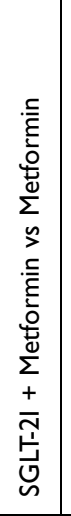 & 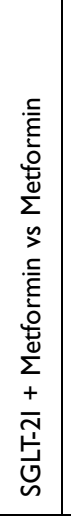 & 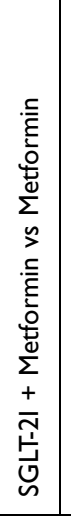 & 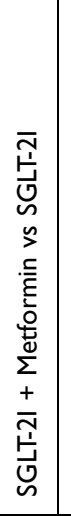 & 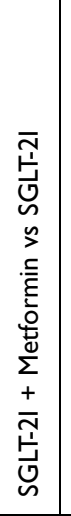 & 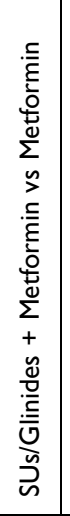 & 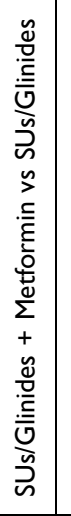 & 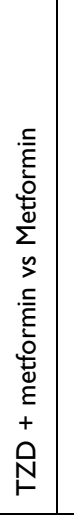 & 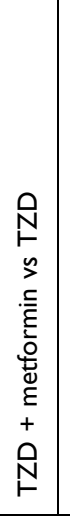 & 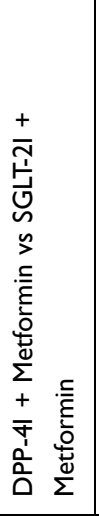 & 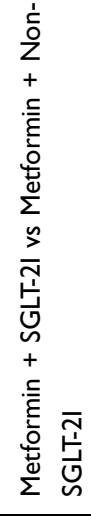 \\
\hline $\begin{array}{l}\frac{\infty}{\bar{\pi}} \\
\stackrel{0}{0} \\
00 \\
\sum_{\pi}^{00}\end{array}$ & $\begin{array}{l}\frac{0}{\bar{\sigma}} \\
\stackrel{\widetilde{U}}{\sigma} \\
\overline{\widetilde{J}}\end{array}$ & 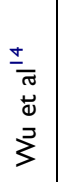 & $\begin{array}{l}\frac{0}{\bar{N}} \\
\stackrel{\tilde{U}}{ } \\
\stackrel{\bar{U}}{U}\end{array}$ & 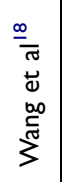 & $\begin{array}{l}\frac{\pi}{\pi} \\
\frac{\pi}{0} \\
\stackrel{\tilde{J}}{0}\end{array}$ & 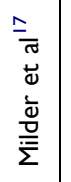 & $\begin{array}{l}\frac{0}{\bar{\sigma}} \\
\stackrel{\tilde{U}}{ } \\
\bar{J}\end{array}$ & 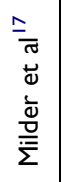 & $\begin{array}{l}\frac{0}{\bar{\pi}} \\
\stackrel{\widetilde{U}}{\sigma} \\
\overline{\widetilde{J}}\end{array}$ & & & & 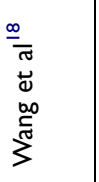 & 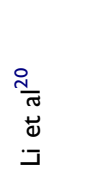 \\
\hline
\end{tabular}




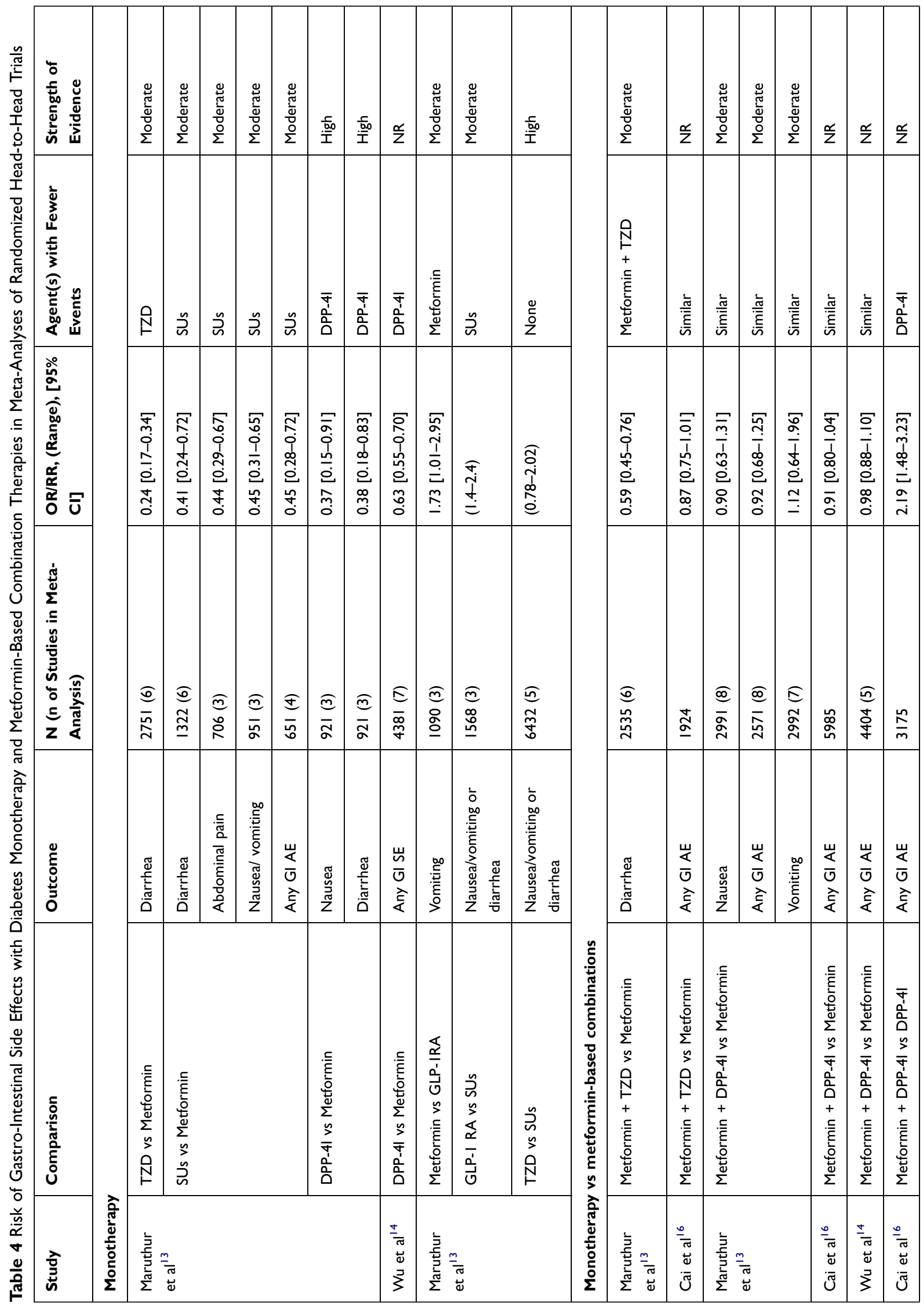




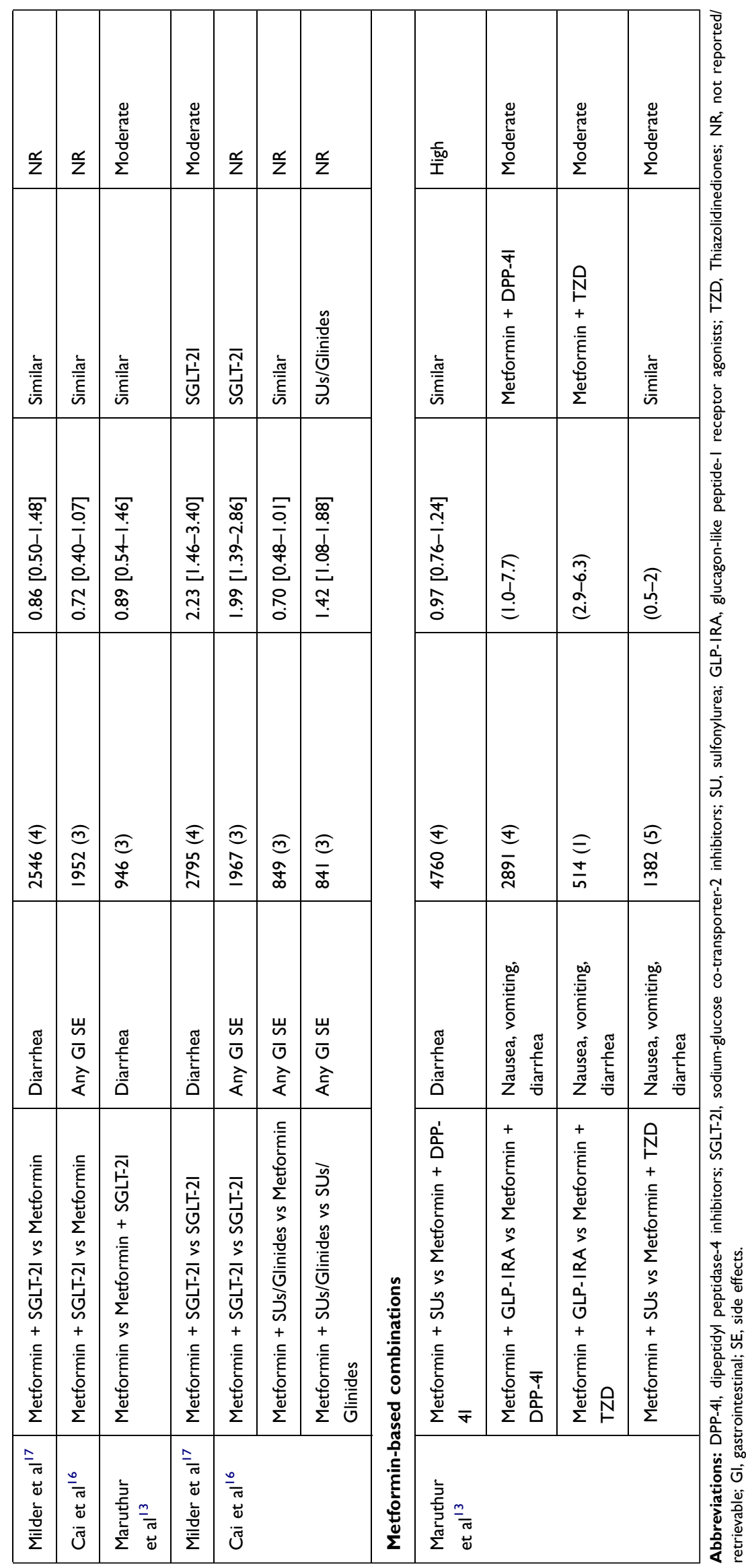


Table 5 Risk of Genito-Urinary Infections with Diabetes Monotherapy and Metformin-Based Combination Therapies in MetaAnalyses of Randomized Head-to-Head Trials

\begin{tabular}{|c|c|c|c|c|c|c|}
\hline Study & Comparison & Outcome & $\begin{array}{l}\mathbf{N} \text { ( } \mathbf{n} \text { of Studies in } \\
\text { Meta-Analysis) }\end{array}$ & $\begin{array}{l}\text { OR/RR, } \\
\text { (Range), [95\% } \\
\mathrm{Cl}]\end{array}$ & $\begin{array}{l}\text { Agent(s) with } \\
\text { Fewer Events }\end{array}$ & $\begin{array}{l}\text { Strength of } \\
\text { Evidence }\end{array}$ \\
\hline \multirow{2}{*}{$\begin{array}{l}\text { Maruthur } \\
\text { et } \mathrm{al}^{13}\end{array}$} & SGLT-2I vs Metformin & GTI & $2292(4)$ & $4.1(2.0-8.3)$ & Metformin & Moderate \\
\hline & $\begin{array}{l}\text { Metformin + SGLT-2I vs } \\
\text { Metformin }\end{array}$ & GTI & $4035(3)$ & $\begin{array}{l}\text { F: } 3.0(1.2-7.2) \\
\text { M: } 2.7(0.8-9.0)\end{array}$ & Metformin & High \\
\hline \multirow{4}{*}{$\begin{array}{l}\text { Milder } \\
\text { et } \text { al }^{17}\end{array}$} & \multirow{2}{*}{$\begin{array}{l}\text { Metformin + SGLT-2I vs } \\
\text { Metformin }\end{array}$} & GTI & $2546(4)$ & $2.2(1.3-3.7)$ & Metformin & Moderate \\
\hline & & UTI & $2546(4)$ & $1.1[0.8-1.6]$ & Similar & NR \\
\hline & \multirow[t]{2}{*}{$\begin{array}{l}\text { Metformin + SGLT-2I vs SGLT- } \\
21\end{array}$} & GTI & $2795(4)$ & $0.7[0.5-0.96]$ & $\begin{array}{l}\text { Metformin + SGLT- } \\
21\end{array}$ & Moderate \\
\hline & & UTI & 2795 (4) & $0.97[0.7-1.4]$ & Similar & NR \\
\hline \multirow[t]{2}{*}{$\begin{array}{l}\text { Maruthur } \\
\text { et } \mathrm{al}^{13}\end{array}$} & $\begin{array}{l}\text { Metformin + SGLT-2I vs } \\
\text { Metformin + SUs }\end{array}$ & GTI & $3815(3)$ & $\begin{array}{l}\text { F: } 5.2(3.4-8.0) \\
\text { M: } 7.6(4.0-14.4)\end{array}$ & Metformin + SUs & High \\
\hline & $\begin{array}{l}\text { Metformin + SGLT-2I vs } \\
\text { Metformin + DPP-4I }\end{array}$ & GTI & $3423(5)$ & $\begin{array}{l}\text { NR }(-2.8 \text { to } \\
8.8 \%)\end{array}$ & $\begin{array}{l}\text { Metformin + DPP- } \\
4 I\end{array}$ & Moderate \\
\hline \multirow[t]{2}{*}{$\begin{array}{l}\text { Mishriky } \\
\text { et al }\end{array}$} & $\begin{array}{l}\text { Metformin + SGLT-2I vs } \\
\text { Metformin + DPP-4I }\end{array}$ & GTI & $2124(5)$ & $4.04[2.10-7.70]$ & $\begin{array}{l}\text { Metformin + DPP- } \\
4 \mid\end{array}$ & NR \\
\hline & $\begin{array}{l}\text { Metformin + SGLT-2I vs } \\
\text { Metformin + DPP-4I }\end{array}$ & UTI & $2672(6)$ & $0.98[0.72-1.34]$ & Similar & NR \\
\hline Li et $\mathrm{al}^{20}$ & $\begin{array}{l}\text { Metformin + SGLT-2I vs } \\
\text { Metformin + Non-SGLT-2I }\end{array}$ & GTI & $\begin{array}{l}\text { M: } 238 \mid(6) \\
F: 2155(6)\end{array}$ & $\begin{array}{l}\text { M: 6.4I [3.58- } \\
\text { II.45] } \\
\text { F: } 5.12 \text { [3.48- } \\
7.54]\end{array}$ & $\begin{array}{l}\text { Metformin + Non- } \\
\text { SGLT-2I }\end{array}$ & NR \\
\hline
\end{tabular}

Abbreviations: DPP-4I, dipeptidyl peptidase-4 inhibitors; SGLT-2I, sodium-glucose co-transporter-2 inhibitors; SU, sulfonylurea; NR, not reported/retrievable; GTI, genital tract infections; UTI, urinary tract infections; OR, odds ratio; RR, rate ratio; F, female; M, male.

(61.9 months vs 36.1 months). There was a $49 \%$ relative risk reduction of initial treatment failure with DPP-4Imetformin combination therapy (hazard ratio [HR] 0.51 ; 95\% CI, 0.45-0.58; $\mathrm{p}<0.0001$ ) compared to monotherapy group over the 5-year study duration. Furthermore, even the time to secondary treatment failure was significantly (26\%) lower in the combination treatment group, compared to monotherapy group (HR 0.74 ; 95\% CI, $0.63-$ $0.86 ; \mathrm{p}<0.0001)$, without any obvious increase in hypoglycemia and any adverse effects including acute pancreatitis. Historically, early treatment intensification and consequent intensive glucose control in newly diagnosed T2DM have been associated with a significant reduction in vascular complications over 10 years after the study completion (legacy effect) compared to the conventional glucose control arm in the UK Prospective Diabetes Studies. $^{28}$
Sustained glycemic control with diabetes monotherapies has been tested in the past. Rosiglitazone monotherapy had a durable glycemic control compared to SUs or metformin monotherapy in A Diabetes Outcome Progression Trial (ADOPT). ${ }^{29}$ Available evidence of all AHA suggests that both SGLT-2I and TZD have a glycemic control durability of 6-8 years (perhaps the best), followed by metformin of nearly 5 years, and SUs as well as DPP-4I of 3.3-4.4 years. ${ }^{30}$ GLP-1 RA could sustain durable glycemic control up to 7 years at least, as demonstrated in a subgroup analysis of a clinical trial. ${ }^{31}$ Logically, addition of metformin to these agents will likely further increase the durability of glycemic control. The ongoing Glycemia Reduction Approaches in Diabetes: A Comparative Effectiveness (GRADE) study, $^{32}$ is comparing the combinations of metformin with other agents (SU, DPP-4I, GLP-1RA, basal insulin) 
in newly diagnosed T2D patients with mild hyperglycemia (HbA1c of 6.8-8.5\%). GRADE study should shed further light on the glycemic durability of different combination therapies used early in the course of the disease, although it does not have SGLT-2I and pioglitazone arms to compare. An ongoing TRIPLE-AXEL trial ${ }^{33}$ that is evaluating the durability of triple combination therapy of metformin plus SGLT-2I plus DPP4-I and comparing it with a conventional stepwise approach in drug-naïve patients with T2DM (HbA1c 8.0-10.5\%) shall provide further insight.

We do acknowledge the strength and limitations of this review. Strength includes review of results from only the systematic reviews and meta-analyses of RCTs that studied safety and efficacy of diabetes monotherapy vs metforminbased combination therapies in T2DM. Limitations include: a) it is possible that we may have missed some of the systematic reviews and meta-analyses of RCTs that were not available on the single (PubMed) database we searched, b) lack of $\mathrm{H} 2 \mathrm{H}$ studies between metformin vs metformin plus GLP-1RA or GLP-1RA vs metformin plus GLP-1RA, c) pooled meta-analyses could have heterogeneity in the baseline characteristics of patients with T2DM including gender, age and varied doses of AHA, depending upon the RCTs included, d) there is a possibility that these meta-analyses could have varied definitions of safety outcomes including the criteria of mild, moderate, and severe hypoglycemia, and e) majority of these meta-analyses compared either shortterm drug-related or serious adverse events pooled together rather than reporting specific side effects related to the individual AHAs such as lactic acidosis with metformin, ketosis and fractures with SGLT-2I, pancreatitis with DPP-4I and GLP-1RA, and heart failure with TZD and DPP-4I.

\section{Conclusion}

In summary, from the available evidence it is conceivable that metformin-based combination therapy reduces $\mathrm{HbA} 1 \mathrm{c}$ better than monotherapy with any AHA. Among the metformin-based combinations, metformin-SGLT-2I combination therapy appears to have the best $\mathrm{HbA1c}$ reduction with longer durability of glycemic control and the convenience of oral route without any apparent increase in hypoglycemia or other adverse events other than GTI. Interestingly, GTI was significantly less associated with metformin-SGLT-2I compared to the SGLT-2I monotherapy. Positive outcomes for the prevention and treatment of $\mathrm{CV}$ and renal diseases as observed in various cardio-renal outcome trials would be an added advantage for metformin-SGLT-2I combination.

\section{Author Contributions}

All authors meet the International Committee of Medical Journal Editors (ICMJE) criteria for authorship and take responsibility for the integrity of the work. They confirm that this paper will not be published elsewhere in the same form, in English or in any other language, including electronically.

\section{Disclosure}

The authors confirm that there are no known conflicts of interest associated with this publication and there has been no financial support for this work.

\section{References}

1. Davies MJ, D'Alessio DA, Fradkin J, et al. Management of hyperglycemia in type 2 diabetes, 2018. A consensus report by the American Diabetes Association (ADA) and the European Association for the Study of Diabetes (EASD). Diabetes Care. 2018;41(12):2669-2701. doi:10.2337/dci18-0033

2. Haneda M, Noda M, Origasa $H$, et al. Japanese clinical practice guidelines for diabetes 2016. J Diabetes Investig. 2018;9(3):657-697.

3. Kim MK, Ko S-H, Kim B-Y, et al. 2019 clinical practice guidelines for type 2 diabetes mellitus in Korea. Diabetes Metab J. 2019;43 (4):398-406. doi:10.4093/dmj.2019.0137

4. Hong Kong reference framework for diabetes care for adults in primary care settings. 2018. Available from: https://www.fhb.gov. hk/pho/english/resource/files/RF_DM_full.pdf. Accessed July 13, 2021.

5. Diabetes Association of the Republic of China (Taiwan). Executive summary of the DAROC clinical practice guidelines for diabetes care - 2018. J Formos Med Assoc. 2019;119(2):577-586. doi:10.1016/j. jfma.2019.02.016

6. Jia W, Weng J, Zhu D, et al. Standards of medical care for type 2 diabetes in China 2019. Diabetes Metab Res Rev. 2019;35:e3158.

7. Khunti S, Khunti K, Seidu S. Therapeutic inertia in type 2 diabetes: prevalence, causes, consequences and methods to overcome inertia. Ther Adv Endocrinol Metab. 2019;10:204201881984469. doi: $10.1177 / 2042018819844694$

8. Cahn A, Cefalu WT. Clinical considerations for use of initial combination therapy in type 2 diabetes. Diabetes Care. 2016;39 (Supplement 2):S137-S145. doi:10.2337/dcS15-3007

9. Laiteerapong N, Ham SA, Gao Y, et al. The legacy effect in type 2 diabetes: impact of early glycemic control on future complications (the diabetes \& aging study). Diabetes Care. 2019;42(3):416-426. doi:10.2337/dc17-1144

10. Cersosimo E, Johnson EL, Chovanes C, Skolnik N. Initiating therapy in patients newly diagnosed with type 2 diabetes: combination therapy vs a stepwise approach. Diabetes Obes Metab. 2018;20 (3):497-507. doi:10.1111/dom.13108

11. Chin KL, Ofori-Asenso R, Si S, et al. Cost-effectiveness of first-line versus delayed use of combination dapagliflozin and metformin in patients with type 2 diabetes. Sci Rep. 2019;9(1):3256. doi:10.1038/ s41598-019-40191-8

12. Phung OJ, Sobieraj DM, Engel SS, Rajpathak SN. Early combination therapy for the treatment of type 2 diabetes mellitus: systematic review and meta-analysis. Diabetes Obes Metab. 2014;16 (5):410-417. doi:10.1111/dom.12233 
13. Maruthur NM, Tseng E, Hutfless S, et al. Diabetes medications as monotherapy or metformin-based combination therapy for type 2 diabetes: a systematic review and meta-analysis. Ann Intern Med. 2016;164(11):740-751. doi:10.7326/M15-2650

14. Wu D, Li L, Liu C. Efficacy and safety of dipeptidyl peptidase-4 inhibitors and metformin as initial combination therapy and as monotherapy in patients with type 2 diabetes mellitus: a meta-analysis. Diabetes Obes Metab. 2014;16(1):30-37. doi:10.1111/dom.12174

15. Pinto LC, Rados DV, Remonti LR, et al. Efficacy of SGLT2 inhibitors in glycemic control, weight loss and blood pressure reduction: a systematic review and meta-analysis. Diabetol Metab Syndr. 2015;7 (Suppl 1):A58. doi:10.1186/1758-5996-7-S1-A58

16. Cai X, Gao X, Yang W, Han X, Ji JL. Efficacy and safety of initial combination therapy in treatment-naïve type 2 diabetes patients: a systematic review and meta-analysis. Diabetes Ther. 2018;9 (5):1995-2014. doi:10.1007/s13300-018-0493-2

17. Milder TY, Stocker SL, Shaheed CA, et al. Combination therapy with an SGLT2 inhibitor as initial treatment for type 2 diabetes: a systematic review and meta-analysis. J Clin Med. 2019;8:45. doi: $10.3390 / \mathrm{jcm} 8010045$

18. Wang Z, Sun J, Han R, et al. Efficacy and safety of sodium-glucose cotransporter- 2 inhibitors versus dipeptidyl peptidase- 4 inhibitors as monotherapy or add-on to metformin in patients with type 2 diabetes mellitus: a systematic review and meta-analysis. Diabetes Obes Metab. 2018;20(1):113-120. doi:10.1111/dom.13047

19. Mishriky BM, Tanenberg RJ, Sewell KA, Cummings DM. Comparing SGLT-2 inhibitors to DPP-4 inhibitors as an add-on therapy to metformin in patients with type 2 diabetes: a systematic review and meta-analysis. Diabetes Metab. 2018;44(2):112-120. doi:10.1016/j.diabet.2018.01.017

20. Li J, Gong Y, Li C, Lu Y, Liu Y, Shao Y. Long-term efficacy and safety of sodium-glucose cotransporter-2 inhibitors as add-on to metformin treatment in the management of type 2 diabetes mellitus A meta-analysis. Medicine. 2017;27:e7201.

21. Salpeter SR, Greyber E, Pasternak GA, Salpeter EE. Risk of fatal and nonfatal lactic acidosis with metformin use in type 2 diabetes mellitus. Cochrane Database Syst Rev. 2010;4:CD002967.

22. Inzucchi SE, Lipska KJ, Mayo H, Bailey CJ, McGuire DK. Metformin in patients with type 2 diabetes and kidney disease: a systematic review. JAMA. 2014;312(24):2668-2675. doi:10.1001/ jama.2014.15298

23. Cosentino F, Grant PJ, Aboyans V, et al. 2019 ESC guidelines on diabetes, pre-diabetes, and cardiovascular diseases developed in collaboration with the EASD the task force for diabetes, pre-diabetes, and cardiovascular diseases of the European Society of Cardiology (ESC) and the European Association for the Study of Diabetes (EASD). Eur Heart J. 2020;41(2):255-323.
24. American Association of Clinical Endocrinologists. Comprehensive type 2 diabetes management algorithm (2019) - executive summary. 2019. Available from: https://www.aace.com/disease-state-resources /diabetes/clinical-practice-uidelines-treatment-algorithms/comprehen sive. Accessed February 14, 2020.

25. Cheng AY, Canadian Diabetes Association Clinical Practice Guidelines Expert Committee. Canadian Diabetes Association 2013 clinical practice guidelines for the prevention and management of diabetes in Canada. Introduction. Can J Diabetes. 2013;37(Suppl 1): S1-S3. doi:10.1016/j.jcjd.2013.01.009

26. Buse JB, Wexler DJ, Tsapas A, et al. 2019 update to: management of hyperglycaemia in type 2 diabetes, 2018. A consensus report by the American Diabetes Association (ADA) and the European Association for the Study of Diabetes (EASD). Diabetologia. 2020;63 (2):221-228. doi:10.1007/s00125-019-05039-w

27. Matthews DR, Paldánius PM, Proot P, Chiang Y, Stumvoll M, Prato SD. Glycaemic durability of an early combination therapy with vildagliptin and metformin versus sequential metformin monotherapy in newly diagnosed type 2 diabetes (VERIFY): a 5-year, multicentre, randomised, double-blind trial. Lancet. 2019;394 (10208):1519-1529. doi:10.1016/S0140-6736(19)32131-2

28. UK Prospective Diabetes Study (UKPDS) Group. Intensive blood-glucose control with sulphonylureas or insulin compared with conventional treatment and risk of complications in patients with type 2 diabetes (UKPDS 33). Lancet. 1998;352(9131):837-853. doi:10.1016/S0140-6736(98)07019-6

29. Kahn SE, Haffner SM, Heise MA, et al. Glycemic durability of rosiglitazone, metformin, or glyburide monotherapy. $N$ Engl J Med. 2006;355(23):2427-2443. doi:10.1056/NEJMoa066224

30. Cherukuri L, Smith MS, Tayek JA. The durability of oral diabetic medications: time to A1c baseline and a review of common oral medications used by the primary care provider. Endocrinol Diabetes Metab J. 2018;2:3.

31. Philis-Tsimikas A, Wysham CH, Hardy E, Han J, Iqbal N. Efficacy and tolerability of exenatide once weekly over 7 years in patients with type 2 diabetes: an open-label extension of the DURATION-1 study. J Diabetes Complications. 2019;33(3):223-230. doi:10.1016/j. jdiacomp.2018.11.012

32. Nathan DM, Buse JB, Kahn SE, et al. Rationale and design of the gly-cemia reduction approaches in diabetes: a comparative effectiveness study (GRADE). Diabetes Care. 2013;36(8):2254-2261. doi:10.2337/dc13-0356

33. Kim NH, Lim S, Kwak SH, et al. Efficacy and tolerability of novel triple combination therapy in drug-naïve patients with type 2 diabetes from the TRIPLE-AXEL trial: protocol for an open-label randomized controlled trial. BMJ Open. 2018;8(9):e022448. doi:10.1136/bmjopen-2018-022448
International Journal of General Medicine

\section{Publish your work in this journal}

The International Journal of General Medicine is an international, peer-reviewed open-access journal that focuses on general and internal medicine, pathogenesis, epidemiology, diagnosis, monitoring and treatment protocols. The journal is characterized by the rapid reporting of reviews, original research and clinical studies across all disease areas. The manuscript management system is completely online and includes a very quick and fair peer-review system, which is all easy to use. Visit http://www.dovepress.com/ testimonials.php to read real quotes from published authors. 